SUBJECT AREAS:

PROJECTION AND

PREDICTION

ATMOSPHERIC DYNAMICS

Received

9 August 2013

Accepted

19 February 2014

Published

25 March 2014

Correspondence and requests for materials should be addressed to S.Q.P. (speng@scsio. ac.cn)

\title{
On the mechanisms of the recurvature of super typhoon Megi
}

\author{
Shiqiu Peng' ', Yu-Kun Qian' ', Zhijuan Lai', Sai Hao ${ }^{3}$, Shumin Chen' ', Hongxiong X $u^{2}$, Dongxiao Wang', \\ Xiangde $\mathrm{Xu}^{2}$, Johnny C. L. Chan ${ }^{4}$, Hao Zhou ${ }^{1,5}$ \& Duanling Liv' ${ }^{1,5}$
}

'State Key Laboratory of Tropical Oceanography, South China Sea Institute of Oceanology, Chinese Academy of Sciences, Guangzhou 510301, China, ${ }^{2}$ State Key Laboratory of Numerical Modeling for Atmospheric Sciences and Geophysical Fluid Dynamics, Institute of Atmospheric Physics, Chinese Academy of Sciences, Beijing 100029, China, ${ }^{3}$ State Key Laboratory of Severe Weather, Chinese Academy of Meteorological Sciences, Beijing 100081, China, ${ }^{4}$ School of Energy and Environment, City University of Hong Kong, Hong Kong, China, ${ }^{5}$ Department of Atmospheric Sciences, Nanjing University of Information Science and Technology, Nanjing 210044, China.

Tropical cyclones (TC) are one of the most threatening natural hazards to human beings. Although significant improvements have been made in the track prediction of TCs during the past several decades, considerable uncertainties still exist, especially for recurving tracks. In this study, we explore the physical mechanisms that drove the large recurvature of super typhoon Megi through numerical sensitivity experiments using a regional atmospheric model. The results indicate that the cold air intrusion from the northwest to the southeast of China is the main cause of the sharp turning of Megi. This finding suggests that a cold air intrusion could be taken as an indicator for predicting the recurvature of a tropical cyclone in the future.

D ue to the disastrous effect of tropical cyclones, an accurate prediction of their tracks is very important to protecting human lives and property ${ }^{1,2}$. Because of a number of diverse and complex factors that influence the movement of a tropical cyclone, considerable uncertainties still exist in track prediction using state-ofthe-art numerical models or empirical methods. In particular, the prediction of the recurving track of a tropical cyclone is extremely difficult and remains a big challenge to forecasters ${ }^{3-5}$, because a recurving track of a TC involves more complex processes than an un-recurving one $e^{4}$.

Previous studies have shown that the recurvature of a TC could be caused or influenced by a number of factors, including the steering flows ${ }^{6}$, subtropical high ${ }^{3,7-9}$, monsoon system ${ }^{7,10-12}$, midlatitude westerly trough ${ }^{3,5,8,9,13,14}$, zonal winds in the middle and upper troposphere ${ }^{15,16}$, vorticity advection ${ }^{17}$, momentum exchange, ${ }^{3,8}$, and beta effect together with the basic current asymmetries ${ }^{18}$. In particular, it is found that recurving tracks are closely associated with retreat of a subtropical ridge and approach of a midlatitude westerly trough ${ }^{3,5,7-9,13,14}$. Several studies on modeling TC recurvature have also been carried out for both idealized conditions and real cases ${ }^{3,5,19,20}$. However, because state-of-the-art numerical models generally fall short in capturing the intricacies of the underlying mechanisms of TC recurvature, large errors still exist in the prediction of recurving TC tracks $s^{3,4,8,13}$. Although high-quality initial conditions by data assimilation ${ }^{20}$ or by the improved initialization technique ${ }^{21,22}$ are beneficial to improve the forecasting accuracy of recurving TC tracks, there is not yet a reliable method to predict a TC recurving track in operational practice.

Recently, when we investigated the big recurvature of super typhoon Megi (2010), we noticed that there was a cold air intrusion (CAI) from the northwest to the southeast of China before the sharp turn of Megi, accompanied by a northeast-southwest-oriented cold front located on the eastern coast of China (Fig. 1). In the fields of 925$\mathrm{hPa}$ and $500-\mathrm{hPa}$ temperature and geopotential height, the CAI presented as a cold tongue and a midlatitude westerly trough aloft with strong cold advection from northwest, respectively, which extended as south as to the southeastern China and located on the north of Megi within a distance of $15^{\circ}$ latitude (see Supplementary Figs. S8q and S9q online). We thus speculate that the CAI may be the primary reason for the recurvature of Megi.

To see the generality of this relationship between a CAI and a TC's recurvature, we conduct a census on all TCs of the northwestern Pacific and the SCS that first moved westward/northwestward/southwestward and then made a clockwise recurvature with turning angle larger than $45^{\circ}$ during 1975-2012. Here the TC recurvature is confined to that occurring at the tropical regions (with latitude $<23^{\circ}$ ), thus it is somehow different with that occurring at the extratropical regions which is associated with the extratropical transition of a $\mathrm{TC}^{23}$. To be as objective as possible, here we define a CAI as that it should satisfy the following criteria: 1 ) in the field of 925 -hPa temperature, 
(a)

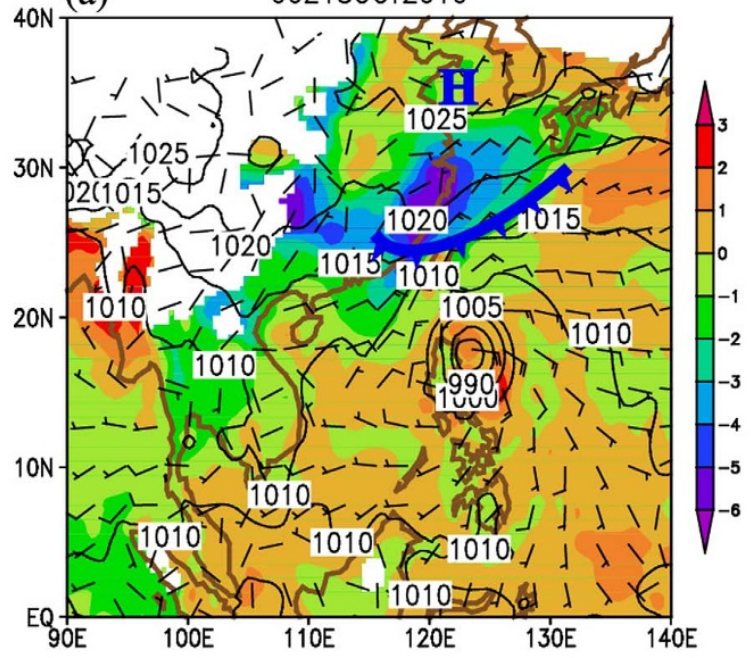

(b)

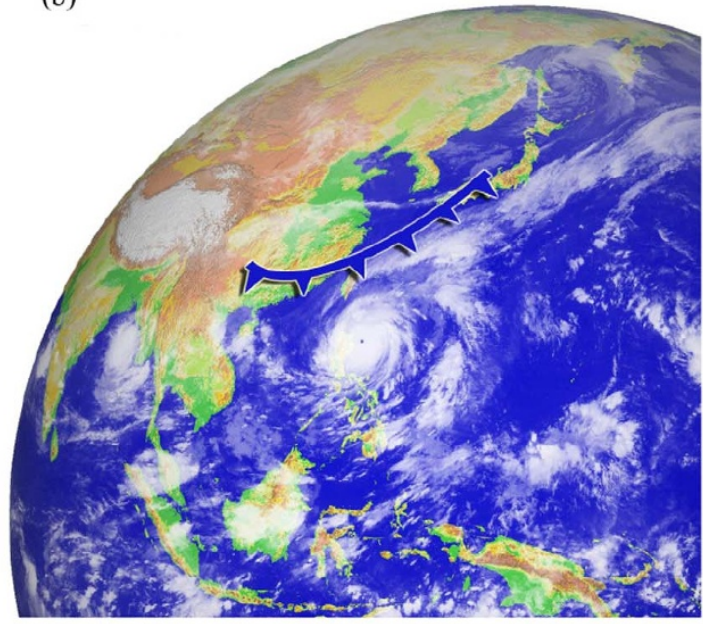

(c) 00Z180CT2010

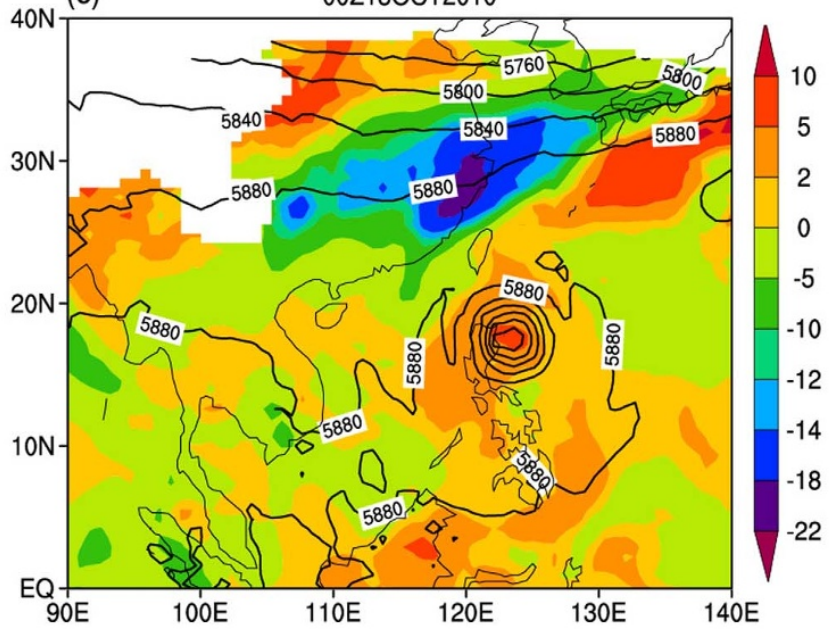

Figure 1 The synoptic situation associated with a cold air intrusion and Megi (2010) at the initial time (0000 UTC 18 Oct. 2010). (a), Surface wind (barb, $\mathrm{m} \mathrm{s}^{-1}$ ), sea level pressure (contour with interval of $5 \mathrm{hPa}$ ) and $900-\mathrm{hPa}$ temperature anomalies relative to zonal mean (shaded, $\mathrm{K}$ ). (b), Infrared image from Multi-functional Transport Satellite-1R (MTSAT-1R) of Japan Meteorological Agency (obtained with permission from http://agora.ex.nii.ac.jp/digital-typhoon/globe/color/2010/2048x2048/MTS110101800.globe.1.jpg). (c), 500-hPa geopotential height (contour with interval of $40 \mathrm{~m}$ ) and $850-\mathrm{hPa}$ equivalent potential temperature anomalies relative to zonal mean (shaded, K). Data for plotting (a) and (c) are from NCEP GFS data $\left(1^{\circ} \times 1^{\circ}\right)$ which were interpolated into model grids. The blue ' $\mathrm{H}$ ' in (a) denotes the surface high pressure system, and the thick blue lines in both (a) and (b) indicate the cold front. Figures (a) and (c) were drawn using GrADS and NCL (doi:10.5065/D6WD3XH5) respectively.

there is an apparent cold tongue defined as $296 \mathrm{~K}$ isotherm for June to September and $294 \mathrm{~K}$ isotherm for October and November, locating on the north of the TC and within a box of $10^{\circ}$ (longitude, eastwest) $\times 15^{\circ}$ (latitude, south-north) centered at the TC center; 2) in the fields of 500 -hPa temperature and geopotential height, there is an apparent midlatitude westerly trough with a cold advection from the northwestern upstream (i.e., there is a southeastward temperature gradient and the temperature trough should be out of phase with trough of geopotential height). The results are given in Table 1. Among the 21 TCs with the recurvature angle larger than $45^{\circ}, 17$ TCs are apparently associated to the CAI, counting $81 \%$ of the total number (see more details in Supplementary Figs. S8-S11 online).

To test the hypothesis that a CAI may induce a TC's recurvature, we conduct a set of sensitivity experiments using a mesoscale atmospheric model with full physics while taking the super typhoon Megi (2010) as our experimental case.

\section{Case description and experimental setup}

Megi was the strongest tropical cyclone in all ocean basins during 2010 , with a maximum wind speed of $80 \mathrm{~ms}^{-1}$ and a lowest sea level pressure of $895 \mathrm{hPa}$ (see a detailed description in Supplementary Information online). It caused a direct damage of 2.8 billion RMB and affected a population of over half a million in southeastern China. The most noticeable feature of Megi's movement is its sharp turn from westward to northward at 0000 UTC 20 Oct. after it swept over the North Philippines and entered the SCS. As shown in the Fig. 2, this sharp turn was approximately predicted by the Global Forecast System (GFS) maintained by the National Centers for Environmental Prediction (NCEP) and a real-time air-sea-wave forecasting system called the Experimental Platform of Marine Environment Forecasting (EPMEF, see a briefly introduction in Supplementary Information online) as early as at 0000 UTC 18 Oct., i.e., 48-h ahead of the recurvature, whereas most other operational forecast agencies failed until 5 -h ahead of the recurvature. An analysis of the forecast outputs indicates that the GFS and EPMEF well predicted the CAI. It should be aware that the forecasts from most operational agencies are usually based on combined results from a number of guidance models (including multi-layer dynamical models, single-layer trajectory models, consensus models, statistical models and so on). Since forecasts from multi-layer dynamical 
Table $1 \mid$ A census on the CAl associated the TC recurvature occurred on the western Pacific and the SCS during 1975-2012. These TCs originally moved westward/northwestward/southwestward and then made a clockwise recurvature with turning angle larger than $45^{\circ}$. A CAl is confirmed only when the following two criteria are satisfied (indicated by $\checkmark$ ): 1) there is a cold tongue on the north of the TC and within a box of $10^{\circ}$ (longitude, east-west) $\times 15^{\circ}$ (latitude, south-north) centered at the TC center, which is defined as $296 \mathrm{k}$ isotherm for June to September and $294 \mathrm{k}$ isotherm for October and November in the 925-hPa temperature field; 2 ) there is a midlatitude westerly trough with a cold advection from the northwestern upstream in the fields of 500-hPa temperature and geopotential height

\begin{tabular}{|c|c|c|c|c|c|}
\hline & TC Name (No.) & Category & 925-hPa Cold Tongue & $\begin{array}{l}\text { 500-hPa Midlatitude Westerly } \\
\text { Trough with Cold Advection }\end{array}$ & Cold Air Intrusion (CAI) \\
\hline 1 & Thelma (197704) & Severe Typhoon & 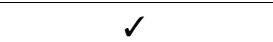 & $d$ & 2 \\
\hline 2 & Babe (197709) & Super Typhoon & 2 & 2 & 2 \\
\hline 3 & Rose (197804) & Severe Tropical Storm & 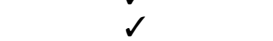 & 1 & 1 \\
\hline 4 & Faye (197907) & Severe Tropical Storm & $s$ & 1 & 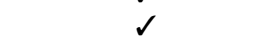 \\
\hline 5 & $\operatorname{Mac}$ (197914) & Severe Tropical Storm & 2 & 2 & 2 \\
\hline 6 & Joe (198314) & Severe Tropical Storm & 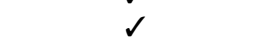 & 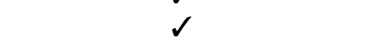 & 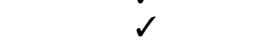 \\
\hline 7 & Thelma (198705) & Super Typhoon & 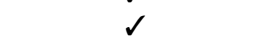 & 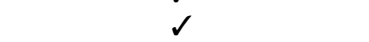 & 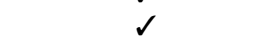 \\
\hline 8 & Nathan (199004) & Severe Tropical Storm & 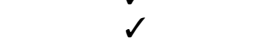 & 1 & 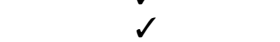 \\
\hline 9 & Mike (199025) & Super Typhoon & 2 & 1 & 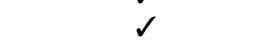 \\
\hline 10 & Faye (199206) & Severe Tropical Storm & 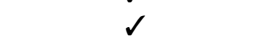 & 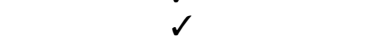 & 2 \\
\hline 11 & Dot (199318) & Typhoon & 2 & 2 & 2 \\
\hline 12 & Joel (199422) & Severe Tropical Storm & $\checkmark$ & 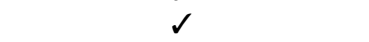 & 2 \\
\hline 13 & Helen (199505) & Severe Tropical Storm & 2 & 2 & 2 \\
\hline 14 & Herb (199609) & Super Typhoon & $x$ & 2 & $x$ \\
\hline 15 & Maggie (199903) & Typhoon & $s$ & 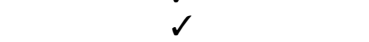 & 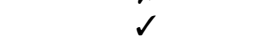 \\
\hline 16 & Rananim (200413) & Severe Typhoon & $s$ & 3 & 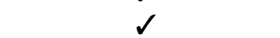 \\
\hline 17 & Sepat (200708) & Super Typhoon & $\checkmark$ & 2 & 2 \\
\hline 18 & Parma (200917) & Severe Typhoon & $x$ & 2 & $x$ \\
\hline 19 & Chanthu (201003) & Typhoon & $x$ & $x$ & $x$ \\
\hline 20 & Megi (201013) & Super Typhoon & $\hat{s}$ & 3 & 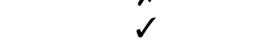 \\
\hline 21 & Vicente (201208) & Typhoon & $x$ & $x$ & $x$ \\
\hline
\end{tabular}

models (such as the GFS) are not available to forecasters until about 4-h after the starting time of a forecast cycle (generally called "late models"), a technique is usually adopted in operational forecast agencies to adjust the most recent available run of a late model to

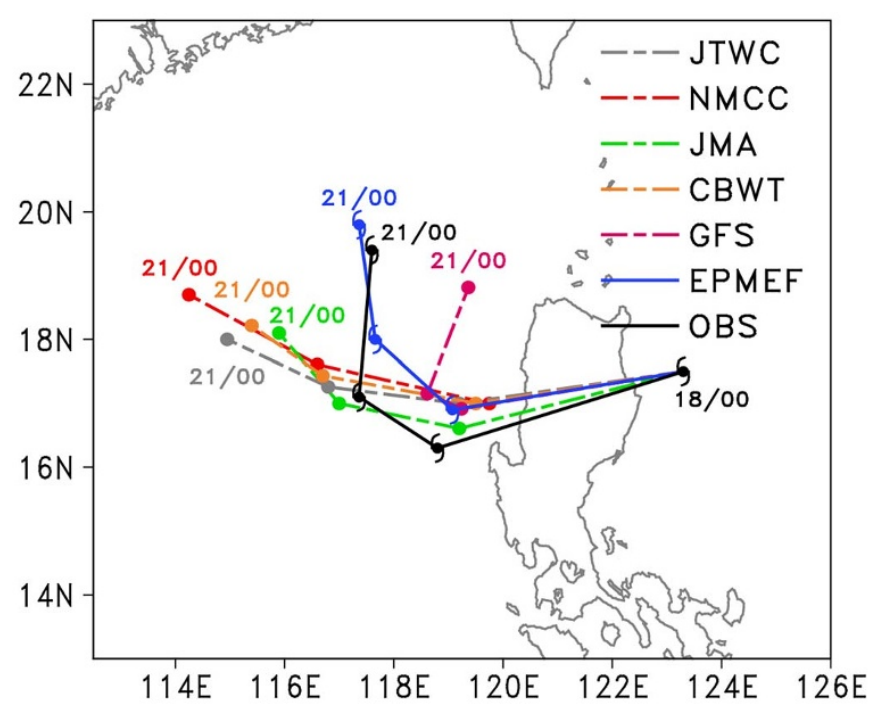

Figure $2 \mid$ The "best" track (denoted by OBS) and the 72-h predicted tracks by different agencies for Megi (2010) started at 0000 UTC 18 Oct. 2010. The positions of the typhoon center are shown at an interval of 24 hours. Here JTWC represents the US navy Joint Typhoon Warning Center, NMCC the National Meteorological Center of China, JMA the Japan Meteorological Administration, CWBT the Central Weather Bureau of Taiwan, GFS the Global Forecast System, and EPMEF the experimental platform of marine environment forecasting. This figure was drawn using GrADS. the current synoptic time and initial conditions (the adjusted version of a late model is thus known, mostly for historical reasons, as "interpolated model". see more details in Supplementary Information online regarding the definition of "late model" and "interpolated model"). Therefore, it is hard for us to know exactly the causes in a Numerical Weather Prediction (NWP) point of view that most operational forecast agencies failed to predict the sharp turn of Megi timely, and exploring the specific causes of failure for each operational forecast agency is beyond the scope of this paper which focuses on investigating whether CAI could cause TC recurvature. Given that Megi was the strongest tropical cyclone in all ocean basins during 2010 with a near $-90^{\circ}$ sharp turn, and that most of the locally operational forecast agencies did not well predict the sharp turn timely, Megi was particularly a difficult case of prediction and could be a representative one of TC recurvature for studying.

To further investigate the impact of the CAI on the recurvature of Megi, we design a set of sensitivity experiments in which the CAI is enhanced or suppressed in varying degrees by adding different temperature increments into the initial temperature fields of the Weather Research and Forecasts (WRF) model (see Method for details). We denote the control run with the CAI (i.e., the same as the atmospheric component run of EPMEF) as CTRL and the sensitivity experiments as sen_- 1.5 , sen_- 1.0 , sen_1.0, and sen_1.5 corresponding to different amplitudes $(A)$ of temperature increment $-1.5,-1.0,1.0$, and $1.5 \mathrm{~K}$, respectively, where a negative (positive) amplitude $(A)$ indicates an enhancement (suppressing) of the CAI (see Supplementary Figs. S2-S7 online for the change of temperature or equivalent potential temperature at low atmosphere at different times).

\section{Experimental results and analysis}

The model starts at 0000 UTC 18 Oct. and makes a 72-h forecast of the track and intensity of Megi. Results show that, when there is a CAI from the northwest of China (CTRL), Megi first moves westward, and then makes a sharp turn around 0000 UTC 20 Oct (Fig. 3). When the CAI is enhanced, Megi appears to make an earlier and 


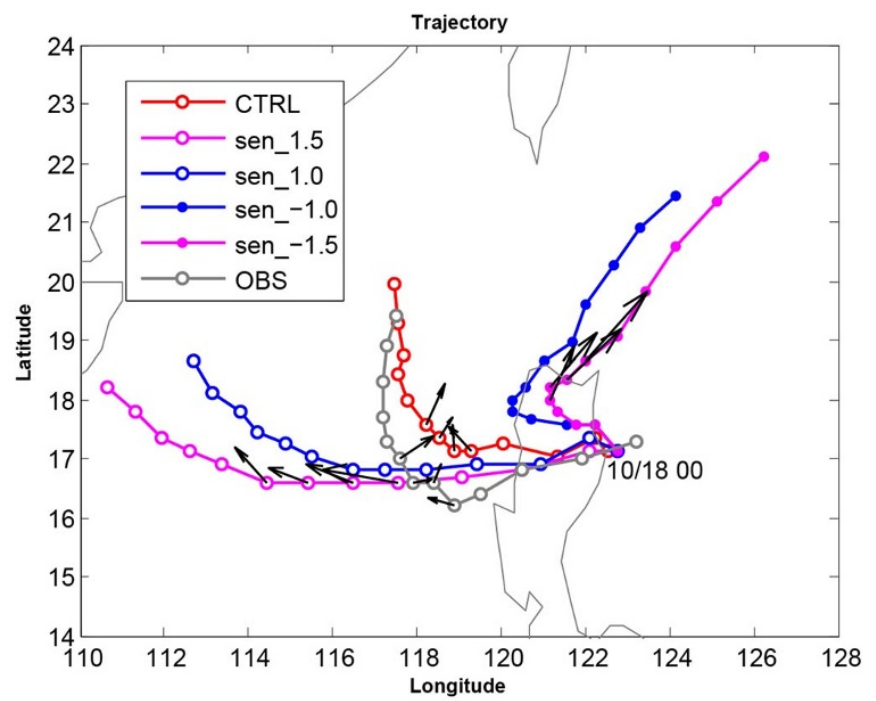

Figure 3 The "best" track (denoted by OBS) and the predicted tracks by different experiments for Megi (2010) starting at 0000 UTC 18 Oct. 2010. Here the gray and red lines are the tracks from the observation (the "best" track) and the control run (CTRL), and the rests are from sensitive experiments in which the amplitudes of temperature increment are set to $-1.5,-1.0,1.0$ and $1.5 \mathrm{~K}$, respectively. Black arrows denote the steering flow at the corresponding time and typhoon center locations around the recurvature. The time interval between circles (or dots) of each track is 6 hours. This figure was drawn using Matlab.

shaper turn than in CTRL; when the CAI is suppressed, Megi tends to move westward straightforward. The more intensively the CAI is enhanced or suppressed (with larger increment amplitudes $A$ ), the sharper turn or the more straightforward movement Megi makes. Therefore, the CAI from the north of Megi could be the primary reason for the sharp turn of Megi from westward to northward.

Why and how did the CAI cause the recurvature of Megi? Since TC movement is generally affected by environmental flows ${ }^{24-27}$ from the lower to upper atmosphere, we speculate that the cold air may have changed the large scale circulation of the upper troposphere through the thermodynamic interactions. The change of large scale circulation can be examined in terms of the geostrophic winds, the subtropical high and the midlatitude upper-level westerly trough (MUWT). According to Holton ${ }^{28}$, the thermal wind relation can be expressed as:

$$
\left\{\begin{array}{l}
u_{t}=-\frac{\partial u_{g}}{\partial p}=-\frac{R}{p f}\left(\frac{\partial T}{\partial y}\right)_{p} \\
v_{t}=-\frac{\partial v_{g}}{\partial p}=\frac{R}{p f}\left(\frac{\partial T}{\partial x}\right)_{p}
\end{array}\right.
$$

where the subscripts $t$ and $g$ stand for thermal winds and geostrophic winds respectively, $f$ the Coriolis parameter, $R$ the constant of dry air, $p$ the pressure and $T$ the temperature. This formula relates the vertical variation of the zonal (meridional) geostrophic winds (i.e., thermal winds) to the meridional (zonal) variation of air temperature. When there is a CAI from the north, there will be a north-to-south temperature gradient $\left(\left(\frac{\partial T}{\partial y}\right)_{p}<0\right)$ and we have westerly thermal winds $\left(\left(\frac{\partial T}{\partial y}\right)_{p}<0 \rightarrow u_{t}=-\frac{R}{p f}\left(\frac{\partial T}{\partial y}\right)_{p}>0\right)$, and thus the westerly zonal geostrophic winds tend to increase with height $\left(-\frac{\partial u_{g}}{\partial p}>0\right)$. As a result, the deep-layer mean steering flows (indicated by the black vectors in Fig. 3) would become more eastward and hence facilitate the sharp turn of Megi. As shown in (Fig. 4), when the CAI is enhanced, the larger north-to-south temperature gradient $\left(\left(\frac{\partial T}{\partial y}\right)_{p}\right.$ $<0)$ leads to stronger westerly zonal geostrophic winds at high level of the atmosphere and thus intensified eastward steering flows, which helps Megi make a sharper turn anticyclonically (Fig. 4a-b); when the CAI is suppressed by adding an inverse (south-to-north) temperature gradient $\left(\left(\frac{\partial T}{\partial y}\right)_{p}>0\right)$, there will be anomalous easterly thermal winds enhanced with the increment amplitude $A$ getting from 1.0 to 1.5 (Fig. $4 \mathrm{c}-\mathrm{d}$ ), leading to anomalous westward steering flows and thus a westward (straightforward) movement of Megi (Fig. 3).

The CAI can also influence the position and strength of the subtropical high. This can be explained using the hydrostatic relationship:

$$
-\frac{\partial \Phi}{\partial p}=\frac{R}{p} T
$$

where $\Phi$ is the geopotential. From Eq. (2), we can see that the thickness $(-\partial \Phi / \partial p)$ is proportional to the temperature, which implies that a CAI may lead to a reduced thickness and thus a weakened
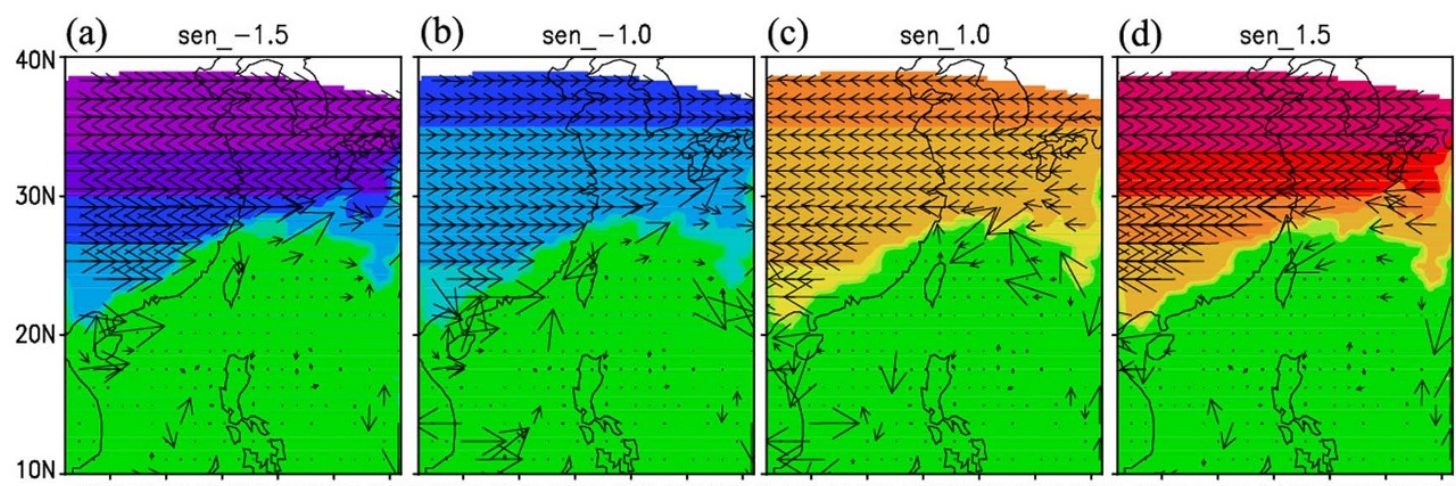

110E 115E 120E 125E 130E 135E 110E 115E 120E 125E 130E 135E 110E 115E 120E 125E 130E 135E 110E 115E 120E 125E 130E 135E

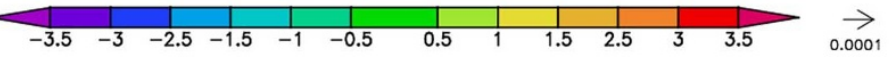

Figure $4 \mid$ Temperature differences (shaded, K) between each sensitive experiment and the control run (the former minus the latter) and the corresponding thermal winds (vector, $\mathrm{m} \mathrm{s}^{-1} \mathrm{~Pa}^{-1}$ ) calculated using Eq. (1) at 900-hPa at initial time (0000UTC 18 Oct. 2010). (a), sen_-1.5. (b), sen_-1.0. (c), sen_1.0. (d), sen_1.5. Thermal wind larger than $2 \times 10^{-4} \mathrm{~m} \mathrm{~s}^{-1} \mathrm{~Pa}^{-1}$ are not shown since they are mostly attributed to the discontinuity of temperature modification. These figures were drawn using GrADS. 
(a)

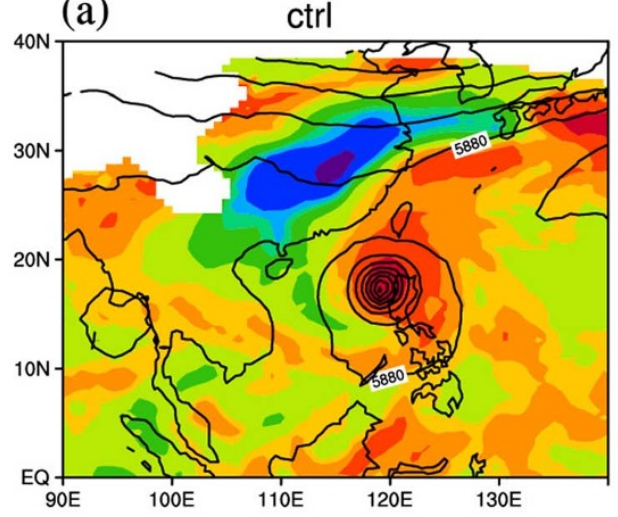

(d) (b)

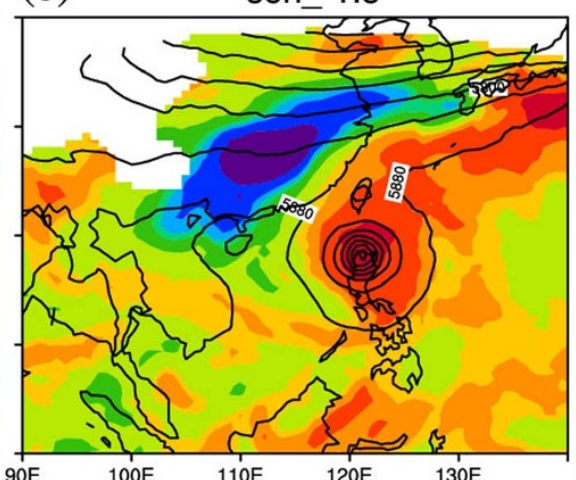

(c)

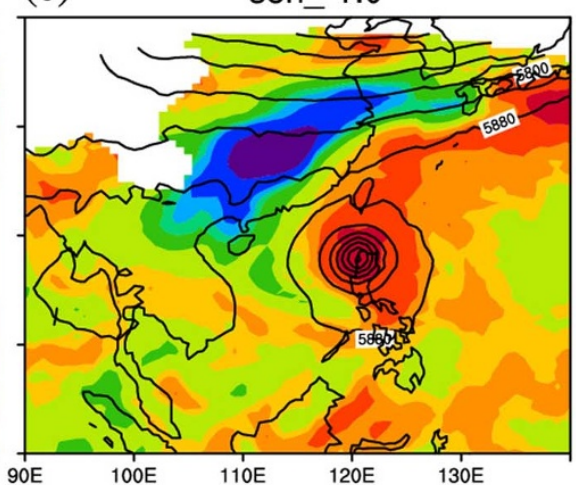

(e)

sen_1.5
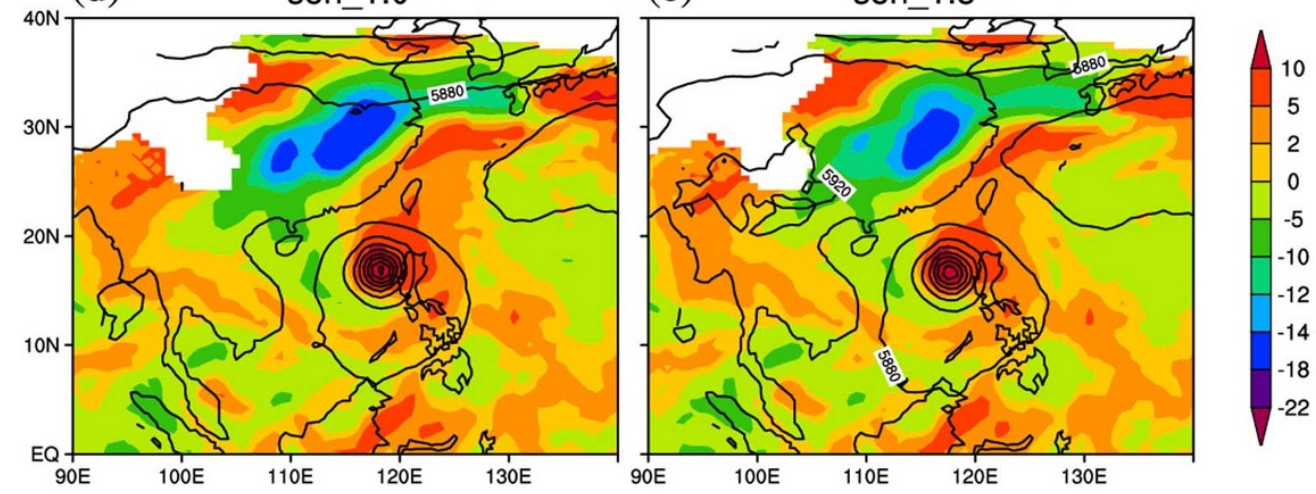

Figure 5 500-hPa geopotential height (contour with interval of $40 \mathrm{~m}$ ) and 850-hPa equivalent potential temperature anomalies relative to zonal mean (shaded, K) at 0000 UTC 19 Oct. 2010. (a), CTRL. (b), sen_-1.5. (c), sen_-1.0. (d), sen_1.0. (e), sen_1.5. These figures were drawn using NCL (doi:10.5065/D6WD3XH5).

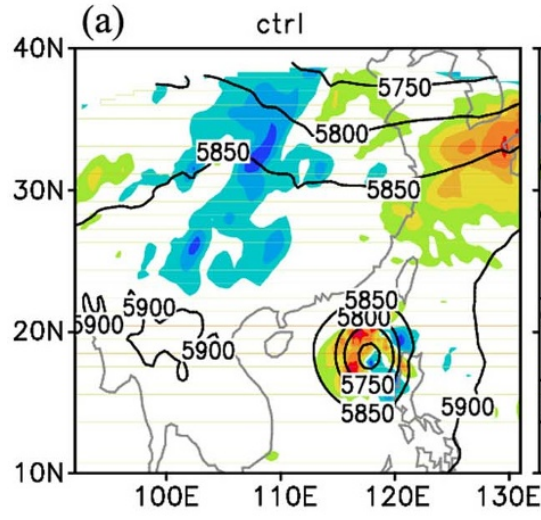

(b)

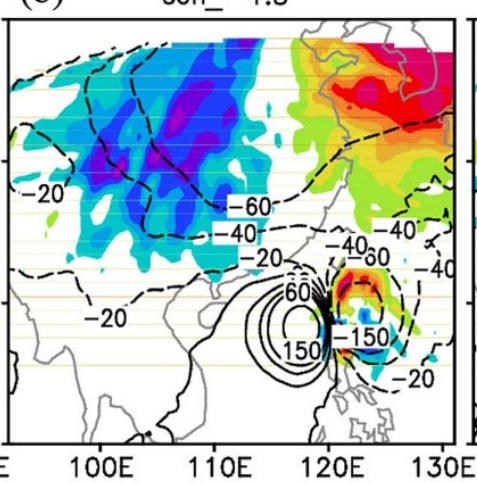

(c) sen_-1.0

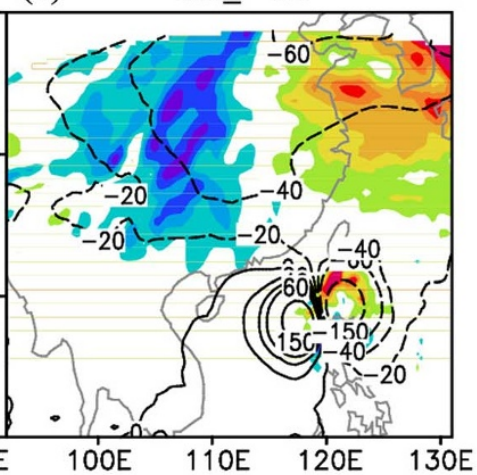

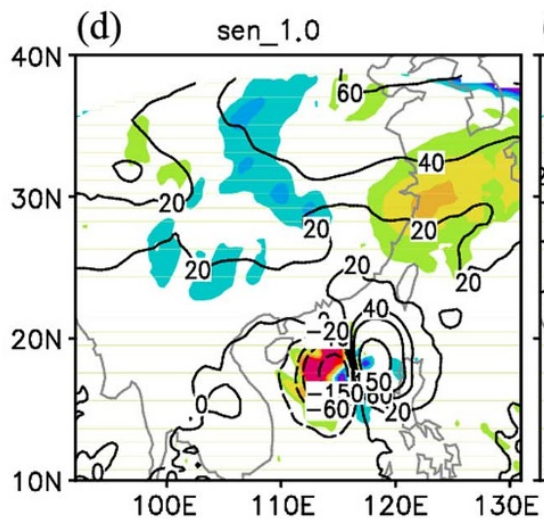

(e) sen_1.5

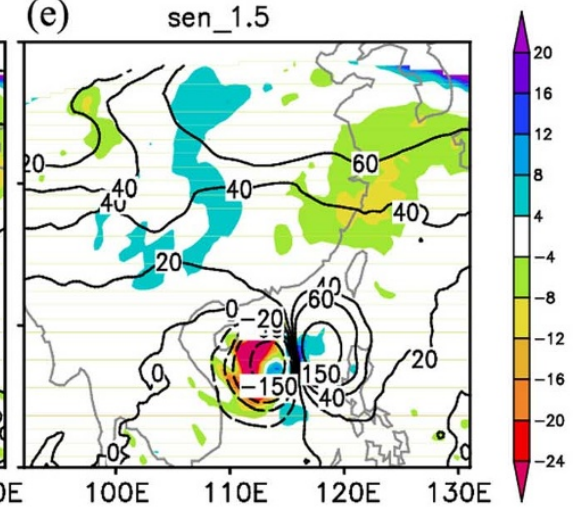

Figure 6 Upper-layer (400-200 hPa) mean temperature advection (shaded in all panels, $10^{-5} \mathrm{~K} \mathrm{~s}^{-1}$ ) and 500 hPa geopotential height (contour in Panel a with interval of $50 \mathrm{~m}$ ) or differences (contour in Panels b-d with interval of $20 \mathrm{~m}$ ) between each sensitivity experiment and the control experiment (the former minus the latter) at 0000 UTC 20 Oct. 2010. (a), CTRL. (b), sen_-1.5. (c), sen_-1.0. (d), sen_1.0. (e), sen_1.5. These figures were drawn using GrADS. 
(a)

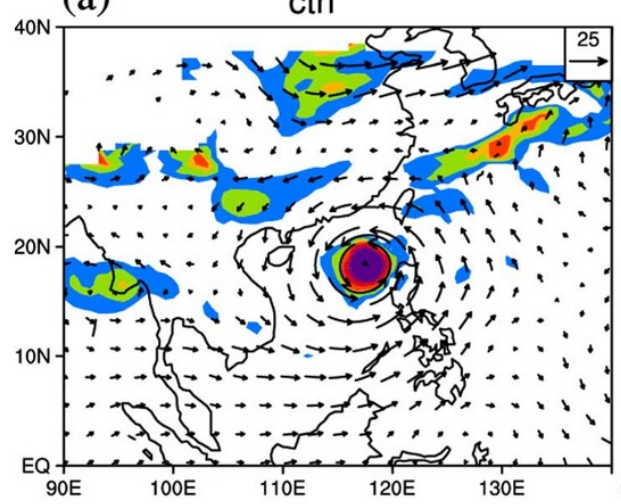

(b)

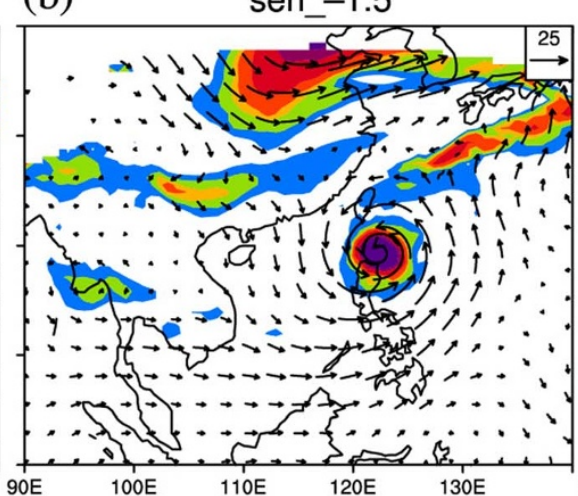

(c)

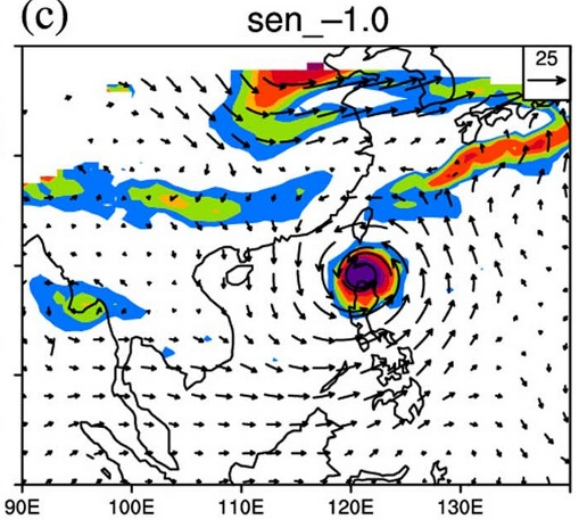

\begin{abstract}
(d) sen_1.0
\end{abstract}

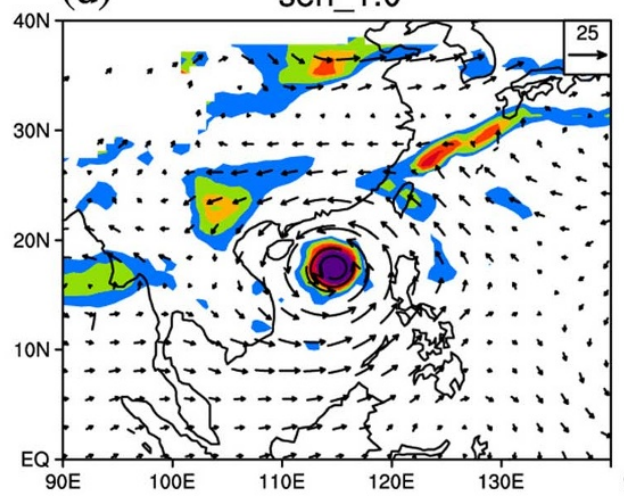

(e)

sen_1.5

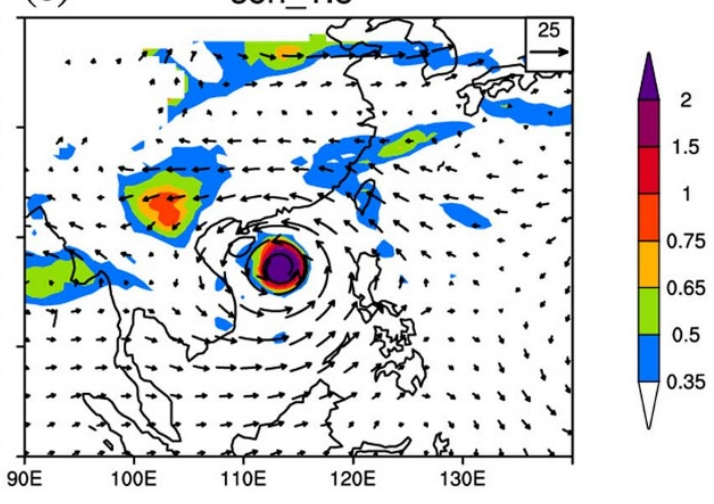

Figure $7 \mid$ Potential vorticity (shading, PVU $=10^{-6} \mathrm{~m}^{2} \mathrm{~s}^{-1} \mathrm{~K} \mathrm{~kg}^{-1}$ ) and horizontal wind (vector, $\mathrm{m} \mathrm{s}{ }^{-1}$ ) at the 315 - $\mathrm{K}$ isentropic surface at $0000 \mathrm{UTC} 20$ Oct. 2010. (a), CTRL. (b), sen_-1.5. (c), sen_-1.0. (d), sen_1.0. (e), sen_1.5. Only the potential vorticity with value larger than 0.35 PVU is shaded. These figures were drawn using NCL (doi:10.5065/D6WD3XH5).

subtropical high. A weakened and east-retreated subtropical high favors the northward movement of a tropical cyclone generated in the north western Pacific Ocean due to the northward flows of the western edge of the subtropical high. The 500-hPa geopotential height for different experiments indicate that the CAI or enhanced CAI do lead to a weakened and east-retreated subtropical high (Fig. 5a-c), and suppressing the CAI results in a stronger and west-extended subtropical high (Fig. $5 \mathrm{~d}-\mathrm{e}$, also see Supplementary Figs. S5-S7 online), as depicted by the contour of $5920 \mathrm{~m}$ in Fig. 5. When the west-reached subtropical high may block Megi from moving northward and the westward flows of its southern edge may steer Megi to the west, the east-retreated subtropical high induced by the CAI seems to open a south-to-north passage for the northward movement of Megi. Studies have also shown that the MUWT can have significant influence on the tracks of tropical cyclones ${ }^{8}$. Our experimental results further indicate that the upper-level cold advection from the high-mid-latitude regions can deepen the MUWT, and thus the northeastward flows ahead of the MUWT may steer Megi to move northward/northeastward (Fig. 6a-c). On the other hand, the weakened upper-level cold advection results in an increase of the geopotential height and therefore a weakening of the MUWT which in turn reduces the cold advection (Fig. $6 c-d$ ), leading to a westward (straightforward) movement of Megi.

As discussed in the study of Wu et al. ${ }^{29}$, the positive PV advection from higher latitudes at upper troposphere may induce upper tropospheric pumping and thus mid-low tropospheric ascent, which is in favor of TC development. Fig. 7 shows PV and horizontal winds on the $315-\mathrm{K}$ isentropic surface at 0000 UTC 20 Oct. 2010 for different experiments. With CAI (CTRL), high PV associated with the westerly trough between $30-40^{\circ} \mathrm{N}$ is found, and a positive southeastward $\mathrm{PV}$ advection results in a high PV ridge north/northeast of Megi (Fig. 7a); the intensified CAI (sen_-1.0, sen_-1.5) leads to an enhancement in the high PV of the westerly trough, the positive southeastward PV advection and the PV ridge northeast of Megi (Figs. 7b-c). Therefore, Megi tends to move northward/northeastward where the atmospheric environment is favorable for TC development with high PV in the upper troposphere. In contrast, when the CAI is suppressed (sen_1.0, sen_1.5), the high PV of the westerly trough, the positive southeastward PV advection and the PV ridge northeast of Megi weaken, whereas a PV ridge northwest of Megi develops and enhances, leading to a westward/northwestward movement of the TC.

\section{Discussion}

It should be noted that the factors causing the recurvature of a TC could be various and complex. In addition to the subtropical high and midlatitude westerly trough, the recurvature of a tropical cyclone may be also affected by a number of other factors ${ }^{3-18}$ as aforementioned. In particular, for a super typhoon like Megi, the thermal structure and its interaction with the environmental flow may be different from a moderate tropical cyclone, which may make the causes of its recurving more complex. Our experimental results, however, are the first attempt to numerically demonstrate that the CAI can lead to the sharp turn of a super typhoon through the thermodynamic adjustment of the large scale circulation of the upper troposphere. The results may also have potential value in guiding forecasters for predicting the recurving track of a TC in the future.

\section{Methods}

We employed a regional weather forecasting model, called the Weather Research and Forecasts (WRF) model, for our numerical experiments. The WRF is a next-generation meso-scale numerical weather prediction system that was designed to serve both operational forecasting and atmospheric research needs ${ }^{30}$ and was developed by the National Center for Atmospheric Research (NCAR) and the National Centers for Environmental Prediction (NCEP) in the U.S. A dynamical downscaling technique is 
employed for the regional atmospheric model to obtain higher-resolution output with small- and meso-scale features from the lower-resolution output of a global atmospheric model. To realize this, a two-domain-nested configuration with horizontal resolutions of $72 \mathrm{~km}$ and $24 \mathrm{~km}$, respectively, is designed (see Supplementary Fig. S1 online). Both domains have 27 layers in the vertical. The output from the Global Forecast System (GFS) maintained by NCEP with horizontal resolution of $1^{\circ} \times 1^{\circ}$ is used to provide initial conditions and lateral boundary conditions for the outer domain. The Ferrier microphysics scheme ${ }^{31}$, Kain-Fritsch cumulus scheme ${ }^{32}$, YSU PBL scheme $e^{33}$, and Dudhia short wave and RRTM long wave radiation schemes ${ }^{34,35}$ are chosen for both domains.

To intensify or suppress the CAI while maintaining the stability of the model integration, we change the temperature field as follows by adding an increment to the original temperature value $T_{0}$ if and only if all the following three conditions are satisfied: 1) between $1000 \mathrm{hPa}$ and $200 \mathrm{hPa}$;2) those grid points with latitude $\geq 10^{\circ} \mathrm{N}$; 3) $T \leq \bar{T}-0.5$ (where $\bar{T}$ denotes the zonal-averaged temperature), i.e.,:

$$
\begin{gathered}
T=T_{0}+A \cdot \Delta T, \\
\Delta T=\frac{\varphi-\varphi_{0}}{\varphi_{0}},
\end{gathered}
$$

where $\varphi$ is the latitude and $\varphi_{0}=10^{\circ} \mathrm{N}$ the start latitude. $A$ is the increment amplitude, that is, the larger the absolute value of $A$ is, the more intensively the cold air intrusion is enhanced (for negative value) or suppressed (for positive value). In this study, $A$ is set to $-1.5,-1.0,1.0$ and $1.5 \mathrm{~K}$ in different sensitive experiments denoted as sen_- 1.5 , sen_- 1.0 , sen_1.0 and sen_1.5, respectively. Supplementary Figs. S2-S4 online display the temperature fields at $900 \mathrm{hPa}$ at different times.

The steering flow is obtained following the traditional method ${ }^{9,36}$, which is a heightand area-averaged large-scale flow between $925 \mathrm{hPa}$ and $300 \mathrm{hPa}$ and over a $3 \sim 8^{\circ}$ ring-area centered at the typhoon center. The isentropic potential vorticity is calculated $\mathrm{as}^{37}$

$$
P=-g\left(f+\mathbf{k} \bullet \nabla_{\theta} \times \mathbf{v}\right) /(\partial p / \partial \theta),
$$

where $f$ is the Coriolis parameter, $\mathbf{k}$ a unit vertical vector, $\nabla_{\theta}$ the three dimensional gradient operators in $x-y-\theta$ space, $\theta$ the potential temperature, and $\mathbf{v}$ the horizontal wind vector. The equivalent potential temperature is computed by ${ }^{28}$

$$
\theta_{e} \approx \theta_{L} \exp \left[\frac{r_{s}\left(T_{L}\right) L_{v}\left(T_{L}\right)}{c_{p d} T_{L}}\right],
$$

where $\theta_{L}$ and $T_{L}$ are (dry) potential temperature and temperature at the lifted condensation level (LCL), $r_{s}\left(T_{L}\right)$ the saturation mixing ratio at temperature $T_{L}, L_{v}\left(T_{L}\right)$ the latent heat of condensation at temperature $T_{L}$, and $c_{p d}$ the specific heat of dry air at constant pressure respectively.

The 6-hourly NCEP/NCAR Reanalysis 1 (for TCs before 1979) and Reanalysis 2 (only available from 1979) data on $2.5^{\circ} \times 2.5^{\circ}$ latitude/longitude grids are used in the analysis of CAI associated to the TC recurvature during 1975-2012 (http://www.esrl. noaa.gov/psd/data/gridded/). The best tracks of the TCs are obtained from the U.S. Navy/Air Force Joint Typhoon Warning Center (JTWC).

1. Liu, D., Pang, L. \& Xie, B. Typhoon disaster in China: Prediction, prevention, and mitigation. Nat. Hazards, 49, 421-436 (2009)

2. Pielke Jr., R. A. \& Landsea, C. W. Normalized hurricane damages in the United States: 1925-95. Wea. Forecasting, 13, 621-631 (1998).

3. Holland, G. J. \& Wang, Y. Baroclinic dynamics of simulated tropical cyclone recurvature. J. Atmos. Sci. 52, 410-426 (1995).

4. Zhang, W., Leung, Y. \& Chan, J. C. L. The Analysis of tropical cyclone tracks in the western North Pacific through data mining. Part I: Tropical cyclone recurvature. J. Appl. Meteor. Climatol. 52, 1394-1416 (2013).

5. Thu, T. V. \& Krishnamurti, T. N. Vortex initialization for typhoon track prediction. Meteor. Atmos. Phys. 47, 117-126 (1992).

6. Kasahara, A. A comparison between geostrophic and nongeostrophic numerical forecasts of hurricane movement with the barotropic steering model. J. Meteor. 16, 371-384 (1959).

7. Chen, T. C., Wang, S. Y., Yen, M. C. \& Clark, A. J. Impact of the intraseasonal variability of the western North Pacific large scale circulation on tropical cyclone tracks. Wea. Forecasting 24, 646-666 (2009).

8. Li, Y. S. \& Chan, J. C. L. Momentum transports associated with tropical cyclone recurvature. Mon. Wea. Rev. 127, 1021-1037 (1999).

9. Evans, J. L., Holland, G. J. \& Elsberry, R. L. Interactions between a barotropical vortex and an idealized subtropical ridge. Part I: Vortex motion. J. Atmos. Sci. 48, 301-314 (1991).

10. Chen, T.-J. C. \& Chang, C. The structure and vorticity budget of an early summer monsoon trough (mei-yu) over southeastern China and Japan. Mon. Wea. Rev. 108, 942-953 (1980).

11. Wang, Y. \& Wu, C. C. Current understanding of tropical cyclone structure and intensity changes-A review. Meteor. Atmos. Phys. 87, 257-278 (2004).

12. Wang, B. et al. How to measure the strength of the East Asian summer monsoon. J. Climate 21, 4449-4463 (2008).

13. Greorge, J. E. \& Gray, W. M. Tropical cyclone recurvature and nonrecurvature as related to surrounding wind-height fields. J. Appl. Meteor. 16, 34-42 (1977).
14. Guard, C. P. Operational application of a tropical cyclone recurvature/nonrecurvature study based on $200 \mathrm{mb}$ wind fields (Fleet Weather Central/Joint Typhoon Warning Center FPO, San Francisco, 1977).

15. Hodanish, S. \& Gray, W. M. An observational analysis of tropical cyclone recurvature. Mon. Wea. Rev. 121, 2665-2689 (1993).

16. Burroughs, L. D. \& Brand, S. Speed of tropical storms and typhoons after recurvature in the western North Pacific Ocean. J. Appl. Meteor. 12, 452-458 (1973).

17. Elsberry, R. L. International experiments to study tropical cyclones in the western North Pacific. Bull. Amer. Meteor. Soc. 71, 1305-1316 (1990).

18. Holland, G. J. Tropical cyclone motion. A comparison of theory and observation. J. Atmos. Sci. 41, 68-75 (1984).

19. O'Shay, A. J. \& Krishnamurti, T. N. An examination of a model's components during tropical cyclone recurvature. Mon. Wea. Rev. 132, 1143-1166 (2004).

20. Leslie, L. M. et al. Improved hurricane track forecasting from the continuous assimilation of high quality satellite wind data. Mon. Wea. Rev. 126, 1248-1257 (1998).

21. Kurihara, Y., Bender, M. A., Tuleya, T. E. \& Ross, R. J. Improvements in the GFDL hurricane prediction system. Mon. Wea. Rev. 123, 2791-2801 (1995).

22. Bender, M. A., Ginis, I., Tuleya, R., Thomas, B. \& Marchok, T. The operational GFDL coupled hurricane-ocean prediction system\& a summary of its performance. Mon. Wea. Rev. 135, 3965-3989 (2007).

23. Jones, S. C. et al. The extratropical transition of tropical cyclones: Forecast challenges, current understanding, and future directions. Wea. Forecasting 18, 1052-1092 (2003).

24. Dong, K. \& Neumann, C. J. The relationship between tropical cyclone motion and environmental geostrophic flows. Mon. Wea. Rev. 114, 115-122 (1986).

25. Holland, G. J. Tropical cyclone motion: Environmental interaction plus a beta effect. J. Atmos. Sci. 40, 328-342 (1983).

26. Kasahara, A. The numerical prediction of hurricane movement with the barotropic model. J. Meteor. 14, 386-402 (1957).

27. Neumann, C. J. On the use of deep-layer mean geopotential height fields in statistical prediction of tropical cyclone motion. 6th Conference on Probability and Statistics in Atmospheric Sciences, Banff, Canada. Amer. Meteor. Soc., 32-38 (1979).

28. Holton, J. R. An introduction to dynamic meteorology, 4th edn.(Elsevier Academic Press, New York, 2004)

29. Wu, G. et al. Impact of tropical cyclone development on the instability of South Asian High and the summer monsoon onset over Bay of Bengal. Clim Dyn 41, 2603-2616 (2013).

30. Michalakes, J., Dudhia, J., Gill, D., Klemp, J. \& Skamarock, W. Design of a nextgeneration regional weather research and forecast model. Towards teracomputing. World Scientific, River Edge, New Jersey, 117-124 (1999).

31. Ferrier, B. S. et al. Implementation of a new grid-scale cloud and precipitation scheme in the NCEP eta model. Preprints. 15th Conference on Weather Analysis and Forecasting, San Antonio, TX, Amer. Meteor. Soc., 280-283 (2002).

32. Kain, J. S. \& Fritsch, J. M. Convective parameterization for mesoscale models: The Kain-Fritsch scheme. The representation of cumulus convection in numerical models. Meteorol. Monogr., Emanuel, K. A. \& Raymond, D. J. (eds). Amer. Meteor. Soc. 46, 165-170 (1993).

33. Hong, S.-Y., Noh, Y. \& Dudhia, J. A new vertical diffusion package with an explicit treatment of entrainment processes. Mon. Wea. Rev. 134, 2318-2341 (2006).

34. Dudhia, J. Numerical study of convection observed during the winter monsoon experiment using a mesoscale two-dimensional model. J. Atmos. Sci. 46, 3077-3107 (1989).

35. Mlawer, E. J., Taubman, S. J., Brown, P. D., Iacono, M. J. \& Clough, S. A. Radiative transfer for inhomogeneous atmosphere: RRTM, a validated correlated-k model for the longwave. J. Geophys. Res. 102, 16663-16682 (1997).

36. Chan, J. C. L. \& Gray, W. M. Tropical cyclone movement and surrounding flow relationships. Mon. Wea. Rev. 110, 1354-1374 (1982).

37. Hoskins, B. J., McIntyre, M. E. \& Robertson, A. W. On the use and significance of isentropic potential vorticity maps. Quart. J. Roy. Meteor. Soc. 111, 877-946 (1985).

\section{Acknowledgments}

This work was jointly supported by the MOST of China (Grant Nos. 2011CB403505, 2014CB953904 \& 2009CB421504), the Strategic Priority Research Program of the Chinese Academy of Sciences (Grant No. XDA01020304), National Natural Science Foundation of China (Grants Nos. 41376021, 41205032 \& 41130960), and the Hundred Talent Program of the Chinese Academy of Sciences. Thanks also go to the graphic software packages, i.e., Grid Analysis and Display System (GrADS), NCAR Command Language (NCL, doi:10.5065/ D6WD3XH5) and Matlab, which were employed to plot the figures, and to the National Institute of Informatics of Japan which gave us the permission for using the satellite image shown in Fig. 1b.

\section{Author contributions}

S.P. designed the study. Z.L. performed the experiments, and Y.Q. and S.H. analyzed the results. S.C. and H.X. made the census on the relationship between TC recurvature and CAI 
for the period of 1975-2012. D.W., X.X. and J.C.L.C. gave some conceptual advice. S.H., H.Z. and D.L. helped to plot some of the figures. S.P. and Y.Q. wrote the manuscript.

\section{Additional information}

Supplementary information accompanies this paper at http://www.nature.com/ scientificreports

Competing financial interests: The authors declare no competing financial interests.
How to cite this article: Peng, S.Q. et al. On the mechanisms of the recurvature of super typhoon Megi. Sci. Rep. 4, 4451; DOI:10.1038/srep04451 (2014).

(c) (i) (2) This work is licensed under a Creative Commons Attribution-

cc) visit http://creativecommons.org/licenses/by-nc-sa/3.0 


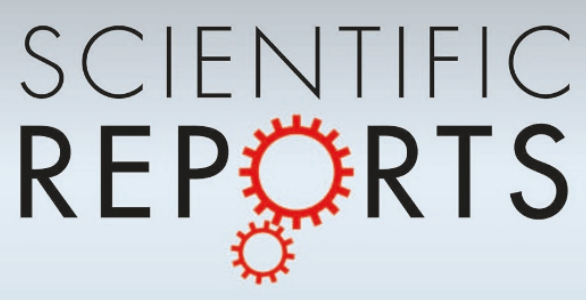

DOI: 10.1038/srep05140

\section{SUBJECT AREAS:}

PROJECTION AND

PREDICTION

ATMOSPHERIC DYNAMICS

SCIENTIFIC REPORTS:

$3: 4451$

DOI: $10.1038 /$ srep04451

(2013)

Published:

25 March 2014

Updated:

15 July 2014

\section{CORRIGENDUM: On the mechanisms of the recurvature of super typhoon Megi}

Shiqiu Peng, Yu-Kun Qian, Zhijuan Lai, Sai Hao, Shumin Chen, Hongxiong Xu, Dongxiao Wang, Xiangde Xu, Johnny C. L. Chan, Hao Zhou \& Duanling Liu

This Article contains an error in the affiliations of the authors Sai Hao, Hongxiong Xu and Xiangde Xu. The correct affiliations for these authors are listed below:

Sai $\mathrm{Hao}^{2}$, Hongxiong $\mathrm{Xu}^{3}$, Xiangde $\mathrm{Xu}^{3}$

${ }^{2}$ State Key Laboratory of Numerical Modeling for Atmospheric Sciences and Geophysical Fluid Dynamics, Institute of Atmospheric Physics, Chinese Academy of Sciences, Beijing 100029, China

${ }^{3}$ State Key Laboratory of Severe Weather, Chinese Academy of Meteorological Sciences, Beijing 100081, China; 